\title{
RERERENCIAIS TEÓRICO-METODOLÓGICOS NAS PESQUISAS EM HISTÓRIA DA EDUCAÇÃO: PARA UMA HISTÓRIA DAS RELAÇÕES ENTRE SENSIBILIDADES, TEMPO LIVRE E FORMAÇÃO ${ }^{1}$
}

\section{THEORETICAL AND METHODOLOGICAL REFERENCES IN HISTORY OF EDUATION RESEARCHES: TOWARDS A HISTORY OF RELATIONS AMONG SENSIBILITIES, FREE TIME AND FORMATION}

\author{
Marcus Aurélio Taborda* \\ Luísa Cecília Belotti Oscar**
}

\begin{abstract}
Resumo: Este escrito apresenta algumas das premissas do projeto $A$ educação dos sentidos na história: o tempo livre como possibilidade de formação (entre os anos finais do séc. XIX e os anos iniciais do séc. XXI). Seu intento básico é compartilhar nosso percurso para a criação de condições para a construção de uma história da educação dos sentidos e das sensibilidades em Minas Gerais no período compreendido entre os anos finais do século XIX e as primeiras décadas do século XXI, ainda que seu escopo vá além das fronteiras deste estado. Desenvolvido a partir de diferentes projetos de mestrado, doutorado e pós-doutorado, e baseado no trabalho empírico das alunas de Iniciação Científica Luísa Cecília Belotti Oscar, Caroline Maria Ferreira Drummond e Maria Daniela Donoso, o texto foca no subprojeto que tem como objetivo principal o mapeamento, a identificação e a catalogação de fontes relacionadas
\end{abstract}

\footnotetext{
* Professor da Faculdade de Educação da Universidade Federal de Minas Gerais (FAE/UFMG). Atua nos Programas de Pós-Graduação em Educação e Inlusão Social e Interdisciplinar em Estudos do Lazer. Coordena do Centro de Estudos e Pesquisas em História da Educação (GEPHE) e o Núcleo de Pesquisas sobre a Educação dos Sentidos e das Sensibilidades (NUPES). Pesquisador do CNPq e da FAPEMIG. E-mail: marcutaborda@pq.cnpq.br ** Licencianda em Educação Física pela UFMG. Bolsista do PIBIC/CNPq. E-mail: luisabelotti@hotmail.com
} 
ao tema central, bem como o desenvolvimento de monografias que permitam compreender a relação entre tempo livre, formação e o desenvolvimento de sensibilidades entre as décadas finais do século XIX e as iniciais do XX. Entre vários arquivos mobilizados aqui, damos destaque ao Arquivo Público Mineiro, à Hemeroteca e ao Setor de Obras Raras da Biblioteca Pública Luiz de Bessa e à Biblioteca da Assembleia Legislativa de Minas Gerais, todos em Belo Horizonte, nos quais é de grande relevância a presença da imprensa periódica como possibilidade empírica.

Palavras-chave: Sentidos e sensibilidades. Imprensa periódica. História da educação social. Acervos e fontes históricas.

\begin{abstract}
This writing presents some perspectives of a new project named Education of the senses in history: the free time as formation possibility (between the last years of $19^{\text {th }}$ Century and the first years of $21^{\text {st }}$ Century). Its basic purpose is to share our journey to creating conditions for the construction of a history of education of the senses and sensibilities in Minas Gerais in the period between the end of the nineteenth century and the first decades of the century XXI. Developed from different master's, doctoral and post doctoral studies, and based on the empirical work of the grade students Luísa Cecília Belotti Oscar, Caroline Maria Ferreira and Maria Daniela Drummond Donoso, the text focuses on a subproject that has as main objective the mapping, identification and cataloging of sources related with the central theme. It also intends the development of monographs for understanding the relationship between free time, formation and development of sensitivities in the indicated period. Among several deployed files, we have given prominence to Arquivo Público Mineiro, Hemeroteca and Setor de Obras Raras da Biblioteca Pública Luiz de Bessa and Biblioteca da Assembleia Legislativa de Minas Gerais, all of them in Belo Horizonte, Minas Gerais, Brazil. Based on these archives, the presence of periodical press as an empirical possibility has great relevance.
\end{abstract}

Keywords: Senses and sensibility. Periodical press. History of social education. Archives and historical sources. 


\section{INTRODUZINDO UM NOVO INVESTIMENTO DE PESQUISA: A IMPRENSA PERIÓDICA COMO UM ÍNDICE PARAA COMPREENSÃO DA MUDANÇA DAS SENSIBILIDADES}

Muito já se produziu sobre a fecundidade da imprensa periódica, aqui, prioritariamente, utilizamos os jornais como fonte, pela vantagem de serem de fácil manuseio e ricos em conteúdo, além de apresentarem registros dinâmicos de uma determinada sociedade. ${ }^{2} \mathrm{O}$ jornal e a imprensa periódica são meios potenciais que

permite(m) uma ampla visão da experiência citadina: dos personagens ilustres aos anônimos, do plano público ao privado, do político ao econômico, do cotidiano ao evento, de segurança pública às esferas cultural e educacional. Nela encontramos projetos políticos e visões de mundo e vislumbramos, em ampla medida, a complexidade dos conflitos e experiências sociais. ${ }^{3}$

Não é difícil concordar com essas considerações. Há, porém, outras questões que precisam ser ponderadas, que dizem sobre suas limitações e alguns dos desafios que oferecem. Os jornais carregam em suas páginas indícios de práticas e pensamentos considerados relevantes por um grupo social, em determinado tempo e contexto. Não são quaisquer práticas que ocupam suas páginas, mas práticas selecionadas para serem registradas e compartilhadas. Isso nos pede um olhar atento aos modos de produção dos jornais nos quais buscamos registros que podem se constituir como fontes. Assim, há que atentarse para o "[...] processo de editoração, composição, relações com o mercado e com os centros de poder, a distribuição e circulação, as diferentes seções que os compõem, além dos seus usos possíveis, autorizados e não controlados, por parte dos leitores, entre outros". ${ }^{4}$

Olhar para os modos de produção do jornal - sua materialidade - é reconhecer a provisoriedade, a parcialidade e a intersubjetividade do que é retratado em suas páginas, além da possibilidade de interação que os grupos produtores têm com a sociedade a partir desse instrumento. Entendemos o desafio de pensar as tensões e relações da sociedade com os jornais, a partir da pesquisa dos modos de produção dos últimos, como um dos pontos mais fecundos das fontes que localizamos, e como uma das mais importantes dimensões da cultura no que se convencionou chamar "modernidade".

Nos arquivos por nós escolhidos para o início deste novo investimento de pesquisa, fizemos um levantamento prévio dos jornais que circulavam em Minas Gerais no período demarcado para a primeira fase do novo projeto, que compreende o período entre 1880 e 1920. A partir dessa busca nos dedicamos à exploração do jornal Minas Geraes, que teve sua primeira edição publicada 
no ano de 1892. Além disso, percorremos a Coleção de Dicionários da Língua Portuguesa da Biblioteca Estadual Luiz de Bessa. Priorizaremos aqui, do ponto de vista empírico, basicamente os registros do jornal Minas Gerais e dos Dicionários do século XIX, por entendermos que são uma mostra significativa do que reserva aos pesquisadores de diferentes campos o acervo da Biblioteca Pública Luiz de Bessa, em Belo Horizonte. ${ }^{5}$

Paralelo ao trabalho empírico, intensificamos os esforços teóricos na tentativa de dimensionar a fecundidade das fontes encontradas para a consecução dos objetivos definidos nos subprojetos e no Programa de Pesquisas. Nesse esforço, vimos aprofundando a compreensão de noções teóricas tais como sentidos, sensibilidades, educação social, tempo livre, trabalho/labor, formação, que se configuram como palavras-chave orientadoras da investigação de todos os integrantes participantes do Grupo de Pesquisas. ${ }^{6}$ Assim, a primeira parte do nosso escrito é composta de um exercício exploratório do escopo teórico conceitual da pesquisa. Em seguida, exploramos alguns documentos potenciais para os fins deste projeto.

Refletindo sobre a cultura - aí incluída a imprensa como expansão das oportunidades educacionais - Raymond Williams nos apresenta um conceito, de grande relevância para os nossos propósitos, "tradição seletiva": "Teóricamente, un período se documenta; en la practica ese documento se absorbe en una tradición selectiva, y ambos son diferentes de la cultura vivida". ${ }^{7}$

Para o autor o processo da tradição seletiva começa ainda no período que ele chama de "cultura viva", no qual uma sociedade estabelece valores e hierarquiza práticas, determinando de algum modo, sempre conflitivo, a organização social daquele tempo e lugar. Em um segundo momento, a seleção ocorre no registro histórico de uma sociedade em particular, que seleciona, hierarquiza e decide o que deve ser perpetuado. No terceiro momento, a "tradição seletiva" se afirma no olhar que dirigimos a esses registros, primeiramente por não termos acesso a todos os registros do ambiente que escolhemos estudar, ignorando assim, partes relevantes do que foi a cultura viva. Destarte, só podemos analisar os vestígios aos quais temos acesso com as lentes de nosso próprio tempo, partindo de nossas próprias sensibilidades, sob a ótica da estrutura de sentimentos que pertence ao nosso próprio contexto.

Diante dessa proposição, Williams reflete ainda sobre do que deve ocupar-se então a história das práticas e dos objetos culturais. Para ele a análise histórica não tem como função reverter a tendência da tradição seletiva, reverter seu processo constitutivo e devolver uma obra ou uma atitude a seu período original. Mas sim evidenciar suas condições de possibilidade, interpretando a permanência e a mudança, relacionando-as com os valores contemporâneos nos quais se embasou - a "estrutura de sentimentos". Deixando dessa forma claras as decisões tomadas durante o processo de pesquisa, estudo e escrita de uma história, estariam dadas as possibilidades de apreensão do passado, 
as possibilidades de tocá-lo em alguns pontos sem pretensão de chegar a toda sua completude, com consciência de que "quase nada" temos condições de apreender do passado, mas que esse quase nada é desejado e possível. ${ }^{8} \mathrm{Negar}$ a autoria, a responsabilidade sobre esse processo é desconsiderar e eliminar as nossas próprias experiências - sempre contingentes - como pesquisadores.

Tendo isso em mente selecionamos os jornais e a imprensa periódica como um dos veículos para o estudo da educação dos sentidos e das sensibilidades em Minas Gerais. No folhear cauteloso das páginas do jornal Minas Gerais algumas palavras direcionavam nossas buscas e possibilitavam que entre tantos documentos aos quais tínhamos acesso, alguns fossem forjados como fontes. ${ }^{9}$ Tempo-livre, educação social, sentidos/sensibilidades, trabalho/ labor e formação são palavras que se convertem em noções teóricas, ainda em caráter descritivo, a serem testadas. Algumas delas aparecem com frequência nos jornais trabalhados, outras não foram captadas por nossos olhares nesses anos de investigação. Na sequencia apresentamos em que perspectiva procuramos entender essas palavras-chave, quais os nossos diálogos acerca delas e as interpretações - provisórias - que vimos produzindo no âmbito do projeto.

Cabe uma palavra, primeiramente, sobre a educação escolar e as suas concepções. Seus currículos, seus espaços, suas aulas, têm tido a primazia nos estudos históricos da educação, no Brasil. ${ }^{10}$ Mas deve-se considerar que existem outros espaços sobre os quais as pesquisas históricas devem lançar suas luzes, uma vez que elas não vêm se ocupando das possibilidades formativas apresentadas pelo tempo livre, por exemplo, deixando aberta uma lacuna na nossa compreensão sobre as diferentes maneiras de educar, mobilizadas pela sociedade. Na precária relação que temos condições de estabelecer com o passado, identificada por Carlo Ginzburg, esse "quase nada" pede que percorramos essas lacunas, que estudemos distintos objetos, objetos semelhantes com focos diferentes; pede, sobretudo, que pensemos nas relações entre eles, entre os vestígios que captamos e as histórias que construímos. ${ }^{11}$ Com isso o tempo livre, aquele tempo não constrangido pelo trabalho ou por obrigações passa a ser um foco dos estudos históricos.

Ao assumirmos o entendimento que se trata de um tempo não constrangido por obrigações laborais, não defendemos que se trata de um tempo isento de constrangimentos socioculturais, de um tempo de plena liberdade e autonomia. No âmbito do "espectro do tempo livre" proposto por Norbert Elias, partimos do entendimento que parte dele se presta ao processo de autoformação dos indivíduos, aspecto que pouco tem chamado a atenção dos historiadores da educação. ${ }^{12}$

Formando um par com o tempo livre, há a noção de trabalho considerado em sua polissemia. A necessidade de entender o tempo de trabalho dos sujeitos para estudar o seu tempo livre advém da convicção de que essas duas noções 
estão em relação constante. A ideia de que tudo é composto também pelo seu oposto poderia ser pensada aqui, ou seja, as possibilidades para o tempo livre são também constituídas em função do tempo constrangido pelo trabalho, naquele "metabolismo com a natureza" proposto por Marx. ${ }^{13}$ Não é um simples truísmo lembrar que é pelo trabalho que apropriamos e significamos o mundo, ainda que em Hanna Arendt a distinção entre trabalho e labor nos leve a supor que o labor se dá pela mobilização dos sentidos como condição de produção da nossa humanização, permitindo a obra que perpetua e a ação sobre o mundo. ${ }^{14}$

Juntamente com "tempo livre" e "trabalho", a noção de "sentidos e sensibilidades" vem direcionando nossos estudos. "Sentidos" nós temos entendido como parte do aparato biológico, responsável pela percepção primária do que nos circunda. Sua educação foi um dos grandes desideratos do movimento de renovação pedagógica disseminado no mundo a partir da década de 1880 , e pode ser inscrita no que consideramos possibilidades de educação do corpo. No séc. XIX denotavam, entre outros possíveis entendimentos, "a faculdade que teem os homens e os animaes de receberem as impressões externas por meio de certos órgãos". ${ }^{15}$

As considerações sobre essa noção em nossos estudos caminham para o entendimento das suas relações e interações com as sensibilidades. Estas, caracterizadas como "faculdades de sentir ou experimentar impressões physicas inherentes ao sistema nervoso, pela qual o homem e os animaes percebem as sensações causadas pelos objectos exteriores ou nascidas no interior" podem ser consideradas domínio educativo na medida em que se pode ensinar e aprender os usos do corpo. Mas se considerarmos uma das suas outras acepções, aquela que define uma "faculdade para experimentar impressões morais; disposição para experimentar impressões dessa espécie", então é preciso reconhecer que as sensibilidades são um resultado das respostas que os indivíduos produzem a partir do momento que interagem com o mundo físico ou social. Essas respostas também são aprendidas. ${ }^{16}$ Estaríamos, então, diante de formas de educação moral, apenas? Por exemplo, toda a tradição da teoria estética, que leva em consideração o conhecimento pela experiência em contraposição ao império da razão, poderia ser inscrita na perspectiva de moralização de uma dada sociedade?

É justamente na educação dos sentidos como uma produtora de novas sensibilidades que localizamos o processo que buscamos interpretar. É em como se dá esse processo, naquilo que os vestígios do passado nos permitem, que concentramos nossos esforços. Nesta busca entendemos, ainda, que sentidos e sensibilidades não são domínios exclusivos das esferas da cultura, ou da "natureza", ainda que a própria história destas noções deva ser objeto de cautela. ${ }^{17}$ Mas pensamos a constituição dos sentidos e das sensibilidades como um problema histórico em uma perspectiva multifacetada, tal como propôs Lucien Febvre quem, certamente não por acaso, aludia ao nosso "complexo 
afetivo-motor". ${ }^{18}$ Os concebemos imbricados com a política, a economia, a cultura, naquilo que as nossas culturas e sociedades mantém de resquício do que é da natureza ou do mundo físico. Uma história dos odores, a ideia de regressão da audição ou as formas que aprendermos do andar, não são marcas tangíveis da interação entre mundo natural e mundo social que sobrevive e muda em nós? ${ }^{19}$ Quando os regimes autoritários ou totalitários desenvolvem uma tecnologia do terror baseada na dor e na crueldade, não é porque capturaram justamente aquele ponto onde cultura e natureza se confundem?

Nessa direção, as formulações de Edward Thompson e Raymond Williams nos apresentam pontos de reflexão relevantes sobre as sensibilidades e a sua história. O primeiro pensando em termos de "experiência" e "economia moral"; o segundo propondo a noção de "estrutura de sentimento". Williams, assim como sugere a noção por ele proposta, afirma a existência de uma estrutura social que baliza as sensibilidades, embora não negue ou ignore o diálogo existente entre o sujeito e a sua cultura; tampouco nega a possibilidade de alguma autonomia dos indivíduos diante dos constrangimentos sociais. No entanto sua ênfase recai sobre a estrutura. Se, por um lado, parte do pressuposto que a "estrutura de sentimento" não afeta na mesma medida e igualmente todos os membros de um grupo social, por outro lado entende que cada grupo social possui uma estrutura de sentimentos que lhe dá o amálgama necessário para a comunicação e interação entre o grupo, portanto, para a organização da sua vida em comum.

Já Thompson, assume que há uma consciência social que age como estruturante da experiência, uma vez que aquela é a mesma para todos os sujeitos. Porém em seu conceito é o sujeito e suas possibilidades, o ser social, que ganha maior relevância. A experiência humana para ele não representaria um processo adaptativo, mas uma atitude dialógica, responsiva e ativa do ser humano diante da estrutura imperativa. A sensibilidade seria então formada em um ponto de contato entre a experiência e a consciência social, na tensão/ relação entre elas.

Ambos os autores têm o mérito de não reduzir a dinâmica da vida à estrutura social. Para os fins da nossa investigação, o que de fato nos interessa na estrutura não é a própria estrutura em sua estabilidade, mas aquilo que permite que ela surja em determinados contextos como signo do que pode ser considerado adequado em termos de atitudes, gestos, comportamentos, desejos, etc., em uma dada situação pretérita, um conjunto de prescrições, por assim dizer. Sua contraparte é a resposta constante e dinâmica que grupos ou indivíduos dão à pretendida estabilização de determinados padrões prescritivos de atitudes esperadas. Em nosso caso a dinâmica que rege a vida seria comparável à dinâmica que rege a comunicação e que engendra as condições para a educação das sensibilidades: o diálogo entre o ser e a consciência social. ${ }^{20}$

Assim, o conceito de experiência apresentado por Thompson nos é caro, pois permite pensar um sujeito com maior grau de autonomia e mesmo 
de espontaneidade diante da estrutura social. Sujeito que apreende e dialoga a partir de suas interações sociais e com o mundo que o circunda. Se existe a possibilidade de a estrutura em alguns contextos determinar uma sensibilidade geral, é provável que diferentes sujeitos apresentem experiências semelhantes. Mas mesmo uma resposta similar pode ser parte de um processo construído pelo sujeito ou pelo grupo em diálogo com a consciência social reinante, e não como uma imposição estrutural pura e simples, passiva e inconscientemente aceita. Para Thompson, "somos agentes voluntários das nossas próprias determinações involuntárias $[\ldots]$... ${ }^{21}$

Sem perder de vista o caráter normativo que esse aspecto pode guardar, ressaltamos ainda que as sensibilidades, tratadas nos dicionários de Língua Portuguesa do século XIX como "a qualidade do ser sensível", ou uma "disposição nos sentidos para a impressão dos objectos", englobam em sua definição uma ambiguidade, magistralmente captada por Febvre: aquilo que convencionamos classificar como positivo na vida dos indivíduos, tais como as alegrias, a compaixão, a felicidade, a beleza, tem uma contraface no que entendemos como negativo: o desespero, a dor, o sacrifício, a feiura. ${ }^{22}$ Ambas remetem a "sentimentos de humanidade" que expressam a delicadeza do humano. Talvez a pretensão de uma história da educação dos sentidos e das sensibilidades permita questionar as bases sobre as quais construímos alguns dos monocórdicos discursos sobre a "positividade" dos processos de formação. Insistimos: seria este, então, um domínio da educação moral? O que representou na experiência alemã a partir dos anos 1930 a forte presença de educação física na educação de crianças e jovens para a unidade, a disciplina e a frieza dos soldados do seu exército dez anos depois? Que sensibilidade é essa que permitiu algumas das práticas mais cruéis da historia nos campos de concentração nazistas? Pode-se negar que houve um processo de educação para que se atingisse aquele tipo de sensibilidade? Seja como for, entendemos que a educação dos sentidos e das sensibilidades é parte essencial nos processos de formação, entendida essa como a autoconstrução dos indivíduos e dos grupos sociais na sua relação com a cultura e a sociedade.

Nesse sentido, que em muito extrapola os rígidos limites da escolarização, uma última noção teórica tem sido objeto das nossas reflexões. Trata-se da noção de "educação social", termo que ainda vem sendo cunhado e está longe de ser unanimidade entre os historiadores. Na perspectiva de Julio Ruiz Berrio, a educação social assume um sentido assistencial-profissional na história espanhola, e está relacionada aos sujeitos colocados à margem das sociedades. Para o autor, a educação social é uma noção moderna, que surge a partir do advento do capitalismo, do crescimento industrial, demográfico e material, que produziria uma nova forma de abandono e marginalização. Berrio lembra que Luiz Vives foi o autor do primeiro programa pedagógico de largo alcance da modernidade, o qual pressupunha que a educação social "debía 
enseñar todo a todos y en todas las edades [...]". ${ }^{23}$ Ou seja, tinha a conotação de uma educação geral da sociedade.

Com as proposições do autor a educação social pode ser interpretada como um programa de recuperação e inserção, embora mesmo na historiografia da educação espanhola o termo assuma outros sentidos. No entanto, Berrio restringe o alcance do conceito para defini-lo como um programa de recuperação e inserção. Para ele se trata de referir-se a "procesos educativos destinados a equilibrar, superar, o prevenir dos categorías fundamentales: la marginación y la exclusión". ${ }^{24}$ Nesses termos, a educação social seria uma forma de o Estado desenvolver uma política de controle e assistência social, englobando uma dimensão de reintegração, de devolução da dignidade e dos direitos aos que foram colocados à margem de uma sociedade de exclusão e marginalização. Nessa dimensão a preparação para o trabalho se destaca como um dispositivo inclusive moralizador, mas, sobretudo, de fomento aos interesses produtivos das modernas sociedades capitalistas.

Em nossa perspectiva a educação social aparece com formas de expressão distintas às apontadas por Berrio, embora não as rejeitemos. Percebemos a educação social no sentido de uma forma não necessariamente institucionalizada de educação que indica a possibilidade de autogestão de grupos ou indivíduos em interação com outros, não tendo necessariamente um caráter assistencialista. Exemplos documentais dessa possibilidade de compreensão são as teses discutidas na II Conferência Nacional de Educação, realizada em 1928, em Belo Horizonte, que tinha entre suas seções justamente uma denominada "Educação Social". Ali, a educação social englobava aspectos ligados ao que se pode chamar de educação profissional, mas também práticas diversas como o escotismo, os batalhões escolares, as excursões etc. Sua polissemia permite vislumbrar na obra de Rocha Pombo, por exemplo, um entendimento diferente daquele dado por Berrio, quando o intelectual paranaense defendia a difusão dos clubes literários, das bibliotecas etc., para alem da implantação de escolas. ${ }^{25} \mathrm{Na}$ realidade brasileira, ainda, podemos pensar nas sociedades de mutuo socorro dos imigrantes, nas associações operárias, nos clubes recreativos e em outras formas de associação que comportam uma dimensão educativa, tais como os Clubes 4-S estudados por Leonardo Ribeiro Gomes em Minas Gerais. ${ }^{26}$

Portanto, mesmo que este conceito esteja em processo de refinamento, havendo assim divergências quanto a seu significado, provisoriamente o percebemos como fecundo para pensar em formas não 'necessariamente' institucionalizadas de educação, guardando assim alguma potência espontânea, uma possibilidade de autogestão da vida, não tendo um caráter necessariamente assistencialista ou profissional. Vale lembrar que mesmo entre os autores espanhóis existe a compreensão que a história da educação social engloba os movimentos juvenis, a autogestão dos trabalhadores, as associações de mútuo 
socorro de imigrantes a formação de clubes associativos com as mais variadas finalidades e configurações, e mesmo o que se conhece como instituciones $y$ actuaciones circumescolares, tais como os chamados comedores, as colônias de férias etc., são expressão dessa forma não necessariamente escolar de educação. ${ }^{27}$

Assim como as sensibilidades, segundo compreendemos, não têm uma dimensão necessariamente positiva, a educação social também comporta um duplo para o qual damos pouca atenção: do ponto de vista dos valores de uma dada sociedade a educação pode promover algo "ruim". Afinal, a que nos referimos quando dizemos que alguém é mal educado ou teve uma má educação? Será apenas para indicar uma falta, um processo inconcluso, ou o reconhecimento que se pode educar para ações, atitudes, valores não aceitos em uma determinada sociedade? O crime, ou as redes criminosas, por exemplo, não possuem códigos que são transmitidos através de um processo que poderíamos denominar educação social? Aprender a prostituir-se, conforme captou Lucas Pereira, não expressa em alguma medida formas de educação social? ${ }^{28} \mathrm{O}$ mesmo não ocorre quando um grupo de pessoas interessadas na produção cinematográfica amadora, por exemplo, oferece a uma dada comunidade a possibilidade de entrar em contato com a cultura do cinema e sua produção, independentemente da institucionalização daquela ação?

Esses são pequenos exemplos da ambivalência que a noção "educação social" pode carregar, mas são caros na tentativa de explicitar a complexidade na sua operacionalização. Além disso, permite pensar a história no seu movimento constante, na medida em que as sociedades e os indivíduos buscam reinventarse em relação aquilo que lhes é prescrito; ou seja, a definição do que é positivo ou negativo no âmbito da historia da educação das sensibilidades não pode ser dissociada do contexto estudado, sendo, portanto, objeto das preocupações do historiador.

Um dos problemas centrais na cunhagem desse termo está em perceber e enunciar o que um processo educativo, no âmbito da educação social, tem de diferente daquilo que chamamos processos de socialização, quais são as particularidades que ele carrega. ${ }^{29}$ Se "educar" carrega consigo uma dimensão estrutural, assim como uma intencionalidade, há que se pensar como se estabelece a relação entre essa intencionalidade do ato educativo e a espontaneidade das trocas sociais que, em última instância, são educativas por excelência. No mesmo dicionário educação refere-se ao "[...] disciplinamento; instrucção, ensino. Conhecimento e pratica dos usos da sociedade". ${ }^{30}$ 


\section{A IMPRENSA PERIÓDICA COMO UM ÍNDICE PARAA COMPREENSÃO DA MUDANÇA DAS SENSIBILIDADES: QUE FONTES?}

Para apresentar os resultados parciais desta investigação, nos reportamos novamente às expectativas iniciais do projeto, observando em quais pontos foi possível atingi-las e sobre as quais precisamos dedicar mais tempo e energia. $\mathrm{O}$ primeiro movimento realizado com a pesquisa foi de levantamento dos jornais que circularam em Minas Gerais entre 1880 e 1900, com o objetivo de ampliar os locais nos quais poderíamos buscar por nossas fontes. $\mathrm{O}$ acervo utilizado para esse levantamento foi o do Arquivo Público Mineiro (APM), que reúne documentos do século XVIII ao século XX, sendo estes de origem do Poder Executivo, ou documentos privados de interesse público. Além das visitas ao Arquivo Público Mineiro, o levantamento foi realizado com suporte do SIA/ APM, que é uma base informatizada com instrumentos de pesquisa e parte dos documentos do arquivo digitalizados, dentre eles os jornais. Estes estão alocados em uma coleção nomeada Jornais Mineiros. A partir disso acessamos primeiramente os jornais do século XIX.

Ao final desta etapa levantamos um total de 226 jornais, registrados em um quadro por nós estruturado, com o qual buscamos registrar as informações mais relevantes que um jornal apresentaria para os nossos propósitos, possibilitando ainda fácil acesso às mesmas. O levantamento dos jornais, portanto, não representou um estudo exaustivo dos mesmos, mas uma ampliação da nossa visão sobre o panorama geral de jornais circulantes no contexto que pesquisamos e que estão disponíveis para consulta dos pesquisadores, para tornarem-se possíveis fontes para o objeto que privilegiamos.

O Quadro 1 é um exemplo de como foi realizado o registro dos jornais. Nela há o nome do jornal, seu subtítulo, o proprietário, editor, redator, o tempo que esteve em circulação, o local, o número de páginas e a quantidade de edições disponíveis no SIA/APM. A maioria dessas informações não foi constante em todas as edições disponíveis: proprietário, número de páginas do jornal, editor, redator e subtítulo. Na verdade, nessa busca inicial pudemos corroborar o argumento sobre a efemeridade dos jornais em Minas Gerais até a primeira metade do século XIX, algo observável também em outras regiões do país. ${ }^{31}$ Tais variações tentamos registrar no mesmo quadro. Importante perceber que o quadro, apesar de não ser extremamente detalhada no que tange à quantidade de dados, apresenta informações relevantes para um início de reflexão sobre os modos de produção dos jornais. 


\section{Quadro 1 - Levantamento de jornais disponíveis no Arquivo Público Mineiro e na Hemeroteca da Biblioteca Pública Estadual Luiz de Bessa}

\begin{tabular}{|l|l|}
\hline JORNAL & A Actualidade \\
\hline SUBTÍTULO & Orgão do Partido Liberal \\
\hline PROPRIETÁRIO & $\begin{array}{l}\text { U.E. da Silva Campos e Carlos Gabriel } \\
\text { Andrade }\end{array}$ \\
\hline EDITOR & Não identificado \\
\hline REDATOR & Não identificado \\
\hline LOCAL & Ouro Preto \\
\hline EDIÇÕES DISPONÍVEIS & 315 \\
\hline CIRCULAÇÃO & Janeiro/1880 a Dezembro/1881 \\
\hline NÚMERO DE PÁGINAS & 4 páginas \\
\hline
\end{tabular}

Exemplo de ficha de catalogação de dados de identificação produzida por Luísa Belotti Oscar. Fonte: Base de dados de periódicos do Arquivo Público Mineiro' e Hemeroteca da Biblioteca Pública Estadual Luís de Bessa, ambos em Belo Horizonte.

Terminado esse registro inicial dos jornais, algumas outras questões surgiram. Por onde, em Minas Gerais, esses jornais circularam? Em quais anos? Como eles estavam distribuídos? As respostas a essas questões ajudariam a acrescentar mais alguns detalhes à visão panorâmica que buscávamos constituir. Trabalhando então os dados obtidos, percebemos que os jornais do Arquivo do SAI/APM eram produzidos em 78 cidades mineiras entre 1880 e 1900 . Ouro Preto, capital até 1897, detinha 66 dos 226 jornais mapeados, sendo a cidade com maior quantidade de jornais em Minas Gerais. Era seguida por Uberaba, com 8 jornais, Juiz de Fora e Campanha, ambas com 7 jornais. Um dado a ser observado é que entre 1880 e 1885, há no arquivo 18 jornais diferentes, sendo 7 deles ouro-pretanos. Entre 1886 e 1890 o número de jornais sobe para 61, estando 25 deles na mesma cidade. Entre 1891 e 1895 os jornais são 65, estando 14 localizados na Capital. E no último período considerado há 82 jornais, dos quais 20 são ali produzidos.

Percebemos, então, um paulatino crescimento do número de jornais em todos os períodos considerados. Quanto mais perto do século XX, maior o número de jornais, o que ajuda a compreender o significado dessas fontes para o entendimento de eventos importantes da nossa história, tais como a abolição da escravatura, a instauração da república, a voga de modernização da passagem do século, movimentos amplos como o sanitarismo e o higienismo, a disseminação da educação de massas, entre tantos outros. Curiosamente, o mesmo não ocorre com o crescimento percentual dos jornais ouro-pretanos. No primeiro período considerado Ouro Preto detinha 39\% dos jornais mineiros; 
$41 \%$ no segundo período; $22 \%$ no terceiro; $24 \%$ no quarto, o que denota a perda da centralidade política da ex-capital. Esses dados poderiam confirmar tanto um aumento da produção de periódicos em Minas Gerais, quanto uma descentralização dessa produção já que, contra cerca de $40 \%$ no início da década de 80 do século XIX, a capital Ouro Preto passa a deter cerca de 20\% dos jornais produzidos nos últimos anos do século XIX. Essas considerações preliminares podem parecer despropositadas. No entanto, a própria construção de uma nova capital em marcos que pretendiam delimitar a herança passada em relação aos novos tempos, proclamados modernos pelos idealizadores daquela iniciativa, por si só ajuda a pensar no horizonte da política os intentos de construção de novas sensibilidades em Minas Gerais.

Esse levantamento e mapeamento dos jornais no final do século XIX apresentou diversas possibilidades de fontes para os nossos propósitos, com características variadas. Observamos jornais em várias cidades, em períodos diferentes, defendendo interesses de grupos diferentes, tais como jornais oficiais; em defesa dos interesses da indústria; publicados somente nos carnavais; em defesa da monarquia; da república, etc. Enfim, essa etapa do trabalho foi responsável por mostrar amplas possibilidades de pesquisas naquele conjunto documental, o que representa um estímulo para investimentos vindouros nos periódicos mineiros, seja como fontes ou como objetos que permitem aprender a educação dos sentidos e das sensibilidades.

Como já foi assinalado, após o mapeamento realizado no Arquivo Público Mineiro, a busca e a catalogação das fontes foram iniciadas pelo acervo da Biblioteca da Assembleia Legislativa de Minas Gerais, que guarda livros técnicos, obras de referência, revistas, diários oficiais, obras editadas pela Assembleia, documentos relativos à atividade dos deputados, além dos jornais, que são o nosso alvo. Estes estão presentes também na Hemeroteca da Biblioteca Pública Luiz de Bessa, em Belo Horizonte, base fundamental para os propósitos da nossa investigação.

Dois jornais foram selecionados como suporte para as primeiras buscas do projeto, sendo o principal deles o Minas Geraes, jornal oficial do Estado de Minas, com início de publicação na capital, Ouro Preto, em 1892. O trabalho com o jornal consistiu na busca de registros que permitissem pensarmos na produção de fontes para a compreensão da educação dos sentidos e das sensibilidades e suas possíveis articulações com o tempo livre. Detivemo-nos, ainda, nos modos de produção deste jornal, os quais também permitem indagar a dinâmica da sociedade estudada que ali transparecia. O Minas Geraes, nessa sua primeira fase, era um jornal diário, produzido pela Imprensa Oficial do Estado, impresso em 4 ou 8 páginas. Era dividido em seções, ocupando-se cada uma de algum tema especifico. Algumas seções eram fixas, estando presentes em todas as edições, tais como "Parte oficial", "Noticiario", "Annuncios". Algumas outras aparecem com menos frequência, como "Editaes", "Revistas 
dos Estados", "Revista do Interior", "Collaboração", "Religião", "Secção Alheia" e "Factos Diversos".

Como era de se esperar, entre as seções do jornal algumas foram mais relevantes para os nossos propósitos: "Noticiario", com relato dos fatos que ocupavam as ruas; "Annuncios", propagandeando eventos, cursos, peças de roupa, festas, serviços; "Collaboração", trazendo crônicas sobre a sociedade mineira e "Religião" relatando os eventos religiosos na cidade, tendo espaço ainda para divulgação de seus preceitos morais. Nessas seções entendemos poder captar ecos do que seria parte do cotidiano da cidade, às vezes do estado, portanto, um índice das sensibilidades ali mobilizadas e transformadas.

As palavras-chave do projeto, já discutidas, foram o guia no trabalho com o jornal e serviram para direcionar o olhar ao longo da análise das suas páginas e para a seleção dos documentos relevantes. Para o registro das fontes encontradas foi desenvolvida em parceria com o restante do grupo de pesquisa uma ficha catalográfica, a qual visa harmonizar os registros realizados por todos os integrantes do grupo em seus subprojetos, possibilitando a criação de um banco de dados comum a todos. A ideia é disponibilizar para a comunidade um catálogo e um banco de dados que capture informações cruzando diferentes marcadores (suporte/fundo/ano/local/etc.), tendo como base um trabalho anterior com a mesma orientação. Esse produto pode auxiliar que evitemos a duplicação de investimentos de pesquisa, além de contribuir para a divulgação e utilização de novos materiais ou novos olhares para velhos materiais na construção da historiografia da educação. ${ }^{32}$

No jornal Minas Geraes, apenas até o ano de 1894, localizamos 174 fontes, as quais classificamos da seguinte maneira: 33 em sentidos/ sensibilidades; 0 em trabalho/labor; 1 em educação social; 10 em formação e 130 em tempo livre. Devido à grande quantidade de fontes catalogadas na palavra-chave "tempo livre", um olhar mais atento foi direcionado a estas. Das 130 fontes, 63 foram localizadas na seção "Noticiario”, 54 nos “Annuncios” e 13 em alguma outra seção, o que enfatiza a relevância das duas primeiras seções para os interesses da investigação. Uma segunda observação desse material foi realizada, considerando o que ele relacionava ao tempo livre, como eram oferecidas possibilidades de ocupá-lo. Assim, classificamos que 45 das fontes relacionavam-se à religião, 36 ao teatro, 20 ao circo, 18 a concertos musicais, 6 a exposições e outras 6 a outros marcadores, como mostra o Quadro 2. 
Quadro 2 - Exemplo do mapeamento das fontes sobre o tempo livre (Luísa Cecília Belotti Oscar, 2012)

\begin{tabular}{|c|c|c|c|c|c|}
\hline & Noticiários & Anúncios & Colaboração & $\begin{array}{c}\text { Outra } \\
\text { (especificar) }\end{array}$ & Total \\
\hline Circo & 8 & 12 & & & 20 \\
\hline $\begin{array}{l}\text { Concerto/ } \\
\text { Música }\end{array}$ & 15 & 2 & & 1 (alheia) & 18 \\
\hline Religioso & 15 & 21 & & $\begin{array}{c}1 \text { (alheia) } \\
8 \text { (religião) }\end{array}$ & 45 \\
\hline Exposição & 4 & 1 & 1 & & 6 \\
\hline Clubes & 1 & & & & 1 \\
\hline Teatro & 16 & 18 & 1 & 1 (alheia) & 36 \\
\hline Baile & 1 & & & & 1 \\
\hline $\begin{array}{l}\text { Inauguração } \\
\text { estátua de } \\
\text { Tiradentes }\end{array}$ & 2 & & & & 2 \\
\hline $\begin{array}{l}\text { Festejo } \\
\text { popular }\end{array}$ & 1 & & & & 1 \\
\hline Total & 63 & 54 & 2 & 11 & 130 \\
\hline
\end{tabular}

Fonte: Minas Geraes, edições publicadas entre os anos 1892 e 1894.

Com a quantidade de fontes encontradas sobre o tempo livre no "Minas Geraes", um segundo movimento de busca de fontes foi realizado. Retornando à base informatizada SIA/APM, localizamos os jornais ouropretanos disponíveis entre 1894 e 1895 e nos lançamos à busca de fontes sobre os usos do tempo livre naqueles últimos anos da antiga capital. Encontramos sete jornais disponíveis: $O$ Cysne, $O$ Estado de Minas, Treze de Março, A Derrocada, O Socialista, Opinião Mineira e $O$ Atheneu. A somatória das edições acessíveis dos mesmos é de 94 no período selecionado. Esse material ainda não foi explorado com profundidade, mas, para os três primeiros meses de 1894, encontramos apenas três fontes que podem ser catalogadas no marcador de tempo livre. Isso já mostra uma disparidade na divulgação de possibilidades de ocupação do tempo livre divulgadas nos jornais, uma vez que o jornal oficial do Estado, o Minas Geraes divulgou em suas páginas 130 fontes que dizem respeito a essa palavra-chave. 


\section{UM ENSAIO DE EXPLORAÇÃO}

Com as fontes catalogadas até o momento, cotejadas com o suporte conceitual mobilizado, se pode afirmar a riqueza dos indícios para o estudo da educação dos sentidos e das sensibilidades nos usos diversos do tempo livre, nas páginas dos jornais. O Minas Geraes tem sido bastante fecundo, oferecendo fontes que permitem pensar na história da educação não institucionalizada pela escola, na qual ganha espaço a educação dos sentidos. As fontes catalogadas possibilitaram uma vista panorâmica sobre a vida em Minas, principalmente em Ouro Preto e Belo Horizonte, antiga e nova capital, nos anos finais do século XIX, momento ao qual nos dedicamos. Nesse ponto da pesquisa começamos a descrever e entender as possibilidades dos arquivos e acervos com os quais vimos trabalhando. A tentativa de analisar e interpretar com cuidado e minúcia as fontes é um momento que apenas começa a se delinear em algumas das monografias produzidas pelo grupo. Mas ao criar instrumentos de descrição das fontes damos um primeiro passo naquela direção, permitindo que façamos algumas ponderações.

Há que se trabalhar tanto nas ausências como nas presenças mapeadas pela pesquisa. A grande quantidade de fontes encontradas sobre o tempo livre e sentidos/sensibilidades, assim como o fato de não termos encontrado (ainda, nos jornais) fontes sobre as noções de trabalho/labor e apenas uma sobre educação social, são motivos tanto para buscarmos vestígios em outras bases documentais, quanto para indagarmos sobre a pertinência das noções teóricas mobilizadas.

As fontes que tratam do tempo livre são "carregadas" de referências a ocupações desejáveis, regulamentadas e programadas para o seu usufruto, em muitos casos de forte acento moralizador. Seus usos parecem guardar códigos de distinção social no que diz respeito à classe social, gênero, religião. Também códigos que afirmam um processo de modernização da cidade de Ouro Preto naquele período, a partir de certo direcionamento no uso dos sentidos. Pode-se dizer que há possibilidade de uma ação retroativa sobre os sentidos e sensibilidades, por exemplo, quando se lê no jornal a seguinte expectativa de Alfredo Camarate sobre a futura capital mineira para o século XX, em um exercício estimulante de imaginação:

Pelas ruas largas, explendidamente calçadas de paralalepipedos, escrupulosamente varridas, irrigadas á bomba, passadas á escova de noute, começam a transitar os vendilhões de toda a especie e ostentando as suas mercancias, com uma elegância de agrupamentos de cores, com uma esteira de linhar, com tão requintado aceio, que fazem lembrar as manhas hollandezas, na cidade de Amsterdam. [...] 
[...] É o vendedor de hortaliças, não já o quitandeiro sujo, esfarrapado; mas um modesto filho do povo, que tem agua grátis ou extremamente barata, para que se lave com desafogo e que, pela educação e hábitos da freguezia, teme a concurrencia de outros mais limpos, mais cuidado, nos trajes e na palavra.

$\mathrm{O}$ vendedor de hortaliças conduz, não uma carrocinha; mas uma carroça puchada por um burro medio, escovado á brasa, alimentado sem sordidez; [...]

Dentro da carroça, pintada e envernizada á estufa, lavada, com os cuidados de um landau particular, accumulam-se verdes e tenras couves, com viços de quem nasceu em terrenos devidamente adubados; repolhos de muitos kilos de peso intervallados por esses globosinhos apetitosos, rouxos, luzidios, que nascem das sementes famigeradas de Bruxellas; alfaces completamente brancos no talo e nas nervuras e esbatendo-se num verde gaio, que promette estalinhos frescos e condescendentes, que se comem, apresentando resistencias de mulher faceira, esquivamentos fugazes, de quem morre por ser vencido e triumphado. Destacando-se, pela intensidade dos fulgores da purpura mólhos de rabanetes completamente livres da terra em que nasceram, por continuadas (ilegível); os ponteagudos e alvos nabos, a chicória farpada e auvi-verde, os brilhantes pomos de ouro, como lhes chamam os italianos, disputando em tamanho, colorido e pezo uns com os outros; o agrião saudavel, os condimentos cheiros; uma orgia de verduras, emfim, que atestam, a um tempo, a prodigalidade do solo e a profisciencia do horticultor. ${ }^{33}$

Há na descrição de Alfredo Camarate o relato de uma mobilização aguda dos sentidos. Na sua pena, as ruas da cidade, suas condições de higiene, a mudança do quitandeiro sujo para o vendedor de hortaliças, as cores das verduras, seus cheiros, permitem pensar que novas sensibilidades se desenhavam. Segantini, explorando as crônicas de Camarate, engenheiro, crítico de arte, arquiteto, cronista, nos oferece um panorama do impacto causado nos sentidos pelo que representou a transformação do arraial que viria a ser Belo Horizonte, quando nele chega, em 1894. ${ }^{34}$

Neste mesmo ano de 1894, há no jornal, ainda, indicativos diversos sobre concertos musicais, programas religiosos da igreja católica, bailes, exposições, peças teatrais, atrações circenses como possibilidades de ocupação do tempo livre da população. Interessante observar que juntamente com o anúncio dos eventos é comum a presença de qualificações em relação ao público que provavelmente frequentaria os programas. 
O theatro, em que se ia das a Favorita, não era um edificio que pretendesse [ilegível] parelhas com o Grand Opera de Pariz, nem mesmo com qualquer destes theatros, (ilegível) pelo agigantado das dimensões e pelos (ilegível) primores da ornamentação. [...]

Quando me sentei na cadeira, já estava grande numero de homens e senhoras na plateia e os camarotes começavam a povoar-se de famílias, cujos vestuários não descrevo, pelo muito que sempre fui avesso no capitulo de modas; mas que, em todo o caso, me impressionaram, pela despretenção do corte e pela suavidade da combinação das côres.

[...] Notei apenas que o publico aplaudiu, no fim dos trechos capitaes e sobretudo quando terminava cada acto.

[...] Essas explosões de enthusiasmo mal cabidas e que perturbam a atenção dos verdadeiros amantes de musica não appareceram sequer uma vez. ${ }^{35}$ Realizou-se ante-hontem a segunda conferencia do rev ${ }^{\mathrm{o}}$ sr. Padre dr. Julio Maria, com auditorio numerosissimo, no qual viam-se representantes de todas as classes, principalmente das mais intelligentes e illustradas, além de muitas famílias de nossa melhor sociedade. ${ }^{36}$

Segantini sugere para o período uma transformação na utilização do espaço público. Nele se observa a definição de um novo universo de divertimentos propostos para o tempo livre, os quais, inclusive, antecipam a inauguração da cidade tida como moderna. ${ }^{37}$ Evidencia-se no material até aqui reunido uma transformação paulatina das sensibilidades citadinas. Esta está representada na mudança nos gestos, nas ruas, nos cheiros, nas cores, nos valores, na constituição material da cidade.

Nesse pequeno registro de nossas buscas observa-se uma ampla gama de possibilidades de desenvolvimento de estudos para o entendimento das transformações nos padrões de sensibilidade de um lugar especifico. É interessante, entre essas possibilidades, pensar o lugar conferido à mulher naquela sociedade. Estariam as mulheres ausentes da cidade? Da dinâmica social? Da vida cultural? Da vida política? Por que os registros dizem tão pouco da sua presença? O jornal Minas Geraes oferece rastros que permitem afirmar que não. Buscar como se dá a inserção delas nessa cidade, como elas atuam, o que as páginas dos jornais dizem sobre elas, é uma das possibilidades de pesquisa estimulante. Entender o alto índice de mulheres presentes na esfera cultural nos campos da música e das artes circenses, nas notícias divulgadas no Minas Geraes, é um investimento que pode contribuir para pensarmos a educação dos sentidos e das sensibilidades, o tempo livre, a educação social e os processos de auto formação em um tempo e contexto específicos.

Pretendemos perceber o que era o tempo livre para homens e mulheres, como ele se constituía, levando em conta a distinção entre as possibilidades 
de formação desejável de cada um. As páginas do jornal podem contribuir em tal tarefa na medida em que dão alguma visibilidade para fatos ordinários e também para aqueles que parecem excepcionais. Ali podemos localizar um amplo leque de valores desejáveis a uns e outros. Percebemos tais possibilidades como indicadoras de novas sensibilidades sendo formadas.

Com grande brilhantismo acaba de concluir o curso da Escola Normal desta capital a exm ${ }^{\mathrm{a}} \mathrm{sr}^{\mathrm{a}}$ d. Cormelita Guimarães, gentil e mimosa filha do nosso bem e particular amigo o Sr. José Symplicito Guimarães que, com justíssima razão se ufana e se alegra entre a familia que o cerca de mil carinhos e que o adora por ver mais uma vez coroado o fructo de seu trabalho, na filha que, sendo o seu orgulho, é uma intelligencia vastíssima e digna de todas as venerações. [...]

Quem a visse com aquella formosura radiante, qual Venus na haste do infinito, em luta com os grandes problemas e a revirar as paginas enfadonhas do livro, dir-se-ia ver uma estatua de ouro num pedestal de sciencia!

O seu porte magestoso e soberbo, sua belleza peregrina, e seu collo alabastrino, a palidez divina que lhe ameiga o rosto radiante de encantos, a sympathia eloquente que a todos prende num elo esmagador, o olhar altivo e severo, a testa ampla como o infinito e ornada de lindas madeixas, os dentes do mais puro marfim e os lábios nacarados e embellezados com o oscular ligeiro da brisa que passa, tudo, tudo demonstra intelligencia rara naquelle ser excepcional. ${ }^{38}$

No excerto fica clara a definição de padrões estéticos que orientam o olhar do observador. São juízos de valor sobre as características tanto físicas quanto psicológicas de uma mulher comparada a uma estátua. Seu porte, sua altivez, seu sorriso, sua simpatia são todos pontos destacados no jornal, que permeiam nossas discussões sobre os sentidos, sobre a formação, sobre o desenvolvimento das sensibilidades. possíveis:

Buscando os espaços do tempo livre outros exemplos ainda são

Realiza-se hoje no salão do Congresso o grande concerto vocal e instrumental em beneficio da Santa Casa de Misericordia desta Capital. Nelle tomarão parte gentilíssimas senhoras da nossa melhor sociedade, que se farão ouvir ao piano, no canto, na harpa, e em um esplendido côro de 12 bandolins [...] (Minas Geraes, 13 de Março de 1894)[...] Correu agradavelmente o ultimo espetáculo da excellente companhia equestre, sendo exhibidos trabalhos, geralmente 
applaudidos pelo publico que completamente enchia o circo

Perry.

Para hoje está annunciado um espetáculo em beneficio das duas graciosas artistas Aristotelina e Mariette Pery, que para sua festa artística organizaram um programma variado e escolhido. $[\ldots]^{39}$

As fontes oriundas dos jornais têm apresentado, portanto, amplas possibilidades de pesquisa sobre os sentidos, as sensibilidades e a sua educação, com os mais variados enfoques. Os registros sobre o tempo livre parecem majoritariamente lidar com a mobilização dos sentidos e conter uma dimensão estética determinante pela sua plasticidade, fazendo crer que se observava no período a redefinição dos padrões de comportamento em relação ao que se considerava arcaico. Nosso esforço foi na direção de tentar compreender o estatuto dessa transformação - quando ela se deu - e como ela pode ter afetado a organização da cultura.

Do ponto de vista dos acervos mobilizados, eles se mostram um extraordinário manancial para o entendimento das praticas pretéritas de educação das sensibilidades. Tanto o acervo do Arquivo Público quanto o da Biblioteca Legislativa de Minas Gerais oferecem uma documentação rica para se entender as tensões, os diálogos estabelecidos entre diferentes esferas do poder politico estatal e as praticas ordinárias da sociedade. É o caso do jornal Minas Geraes, aqui privilegiado. No entanto, nos parece que a Hemeroteca da Biblioteca Pública Luiz de Bessa, em Belo Horizonte, se configura como uma constelação de possiblidades de investigação que vão muito além daquelas práticas adstritas ao espaço político ou econômico. Naquele acervo estão disponíveis centenas de periódicos, alguns de vida efêmera, outros com grande permanência, os quais permitem indagar sobre diferentes formas da organização da cultura. Ecos da modernização brasileira, os anseios da voga modernista, a organização dos imigrantes, as reivindicações dos trabalhadores, o cotidiano das cidades, tudo pode ser objeto de investigação naquele acervo, a nosso ver, ainda pouco dimensionado pelos historiadores em geral, especialmente pelos historiadores da educação. Nesse sentido, ele é uma ferramenta fundamental para um programa de pesquisa que pretende articular os processos de formação com tempo livre, trabalho e o desenvolvimento e a mudança das sensibilidades ao longo do tempo, como este que aqui buscamos apresentar.

\section{NOTAS}

$1 \mathrm{O}$ trabalho apresenta alguns dos resultados do projeto $A$ educação dos sentidos na história: o tempo livre como possibilidade de formação (entre os anos finais do séc. XIX e os anos iniciais do séc. XXI), em andamento, desenvolvido junto ao Núcleo de Pesquisas sobre a Educação dos Sentidos e das Sensibilidades - NUPES, vinculado ao GEPHE, na UFMG. O 
projeto conta com financiamento da FAPEMIG (processo n. APQ-00635-11), CNPq (processo n. 470687/2011-8) e CAPES (processo n. PNPD 2587/2011). Este texto foi concebido a partir das pesquisas empíricas de Luisa Cecília Belotti Oscar (PIBIC-CNPq), Caroline Maria Ferreira Drummond (PROBIC-FAPEMIG) e Maria Daniela Donoso (PROBIC-FAPEMIG).

2 TABORDA DE OLIVEIRA, Marcus Aurelio; PYKOSZ, Lausane Correa. A escolarização das práticas corporais no estado do Paraná (1846-1926): Perscrutando o acervo de periódicos da biblioteca do Paraná. História da educação, Pelotas, v. 13, n. 29, p. 115-142, set./dez. 2009.

3 VIEIRA, Carlos Eduardo. Jornal diário como fonte e como tema para a pesquisa em História da Educação: um estudo da relação entre imprensa, intelectuais e modernidade nos anos de 1920. In: TABORDA DE OLIVEIRA, Marcus Aurelio (Org.). Cinco estudos em história e historiografia da educação. Belo Horizonte: Autentica, 2007.

${ }^{4}$ Cf. TABORDA DE OLIVEIRA; PYKOSZ, op. cit.

${ }^{5}$ Está em processo de finalização outro resultado deste investimento: DRUMOND, Caroline Maria Ferreira; TABORDA DE OLIVEIRA, Marcus Aurelio. A formação do trabalhador no jornal "O Operário" de Montes Claros (1932-1945): produzindo novas sensibilidades (inédito). Outro resultado deste esforço pode ser encontrado em: VIEIRA, Yuri Vitor Guimarães. Retóricas sobre educação physica, sport e exercício fisico no jornal Minas Geraes entre 1913 e 1916. Mestrado em Estudos do Lazer, Universidade Federal de Minas Gerais, 2013. Também há um conjunto de estudos disponíveis, inclusive referentes a outros países, em: TABORDA DE OLIVEIRA, Marcus Aurelio (Org.). Sentidos e sensibilidades: sua educação na história. Curitiba: Editora UFPR, 2012.

${ }^{6}$ Um dos resultados deste novo investimento foi a criação, em 2011, do NUPES - Núcleo de Pesquisas sobre a Educação dos Sentidos e das Sensibilidades, um dos grupos que compõem o GEPHE - Centro de Estudos e Pesquisas em História da Educação, sediado na UFMG. Ambos estão cadastrados no Diretório de Grupos de Pesquisa do CNPq.

7 WILLIAMS, Raymond. La larga revolución. Buenos Aires: Ediciones Nueva Visión, 2003.

${ }^{8}$ GINZBURG, Carlo. O fio e os rastros: verdadeiro, falso, fictício. São Paulo: Companhia das Letras, 2007.

${ }^{9}$ Complementar ao trabalho com o Minas Gerais, que permitiu, entre outros estudos, a dissertação de Vieira (2013), foi o trabalho de Carolina Drummond, com o jornal O Operário, de Montes Claros, no qual a é focalizada a tentativa de produção de uma sensibilidade que aliava a modernização social pela via da consciência dos trabalhadores com o ideário da Igreja Católica, no período entre 1930 e 1942. Por paradoxal que possa parecer, aquele mensário em alguns momentos foi francamente contrário à política varguista.

${ }^{10}$ WARDE, Mirian Jorge; CARVALHO, Marta Maria Chagas. Política e cultura na produção da história da educação no Brasil. Contemporaneidade e Educação, Rio de Janeiro, n.7, p. 9-33, jan./jun. 2000.

${ }^{11}$ GINZBURG, op. cit.

${ }^{12}$ ELIAS, Norbert. El espectro del tiempo libre. In: ELIAS, Norbert; DUNNING, Eric. Ocio y deporte en el proceso de la civilización. Méjico: Fondo de Cultura Económica, 1992.

${ }^{13}$ MARX, Karl. A mercadoria. Coleção Os Pensadores (v. I). São Paulo: Nova Cultural, 1987.

${ }^{14}$ ARENDT, Hanna. Trabalho, obra, ação. Cadernos de Ética e Filosofia Política, São Paulo, n.7, p. 175-201, fev. 2005.

${ }^{15}$ FARIA, Eduardo de. Novo diccionário da língua portugueza. 2 ed. Lisboa: Typographia 
Lisbonense de José Carlos D’Aguiar Vianna, 1856. Sobre a importância da estética no movimento de renovação educacional ver: COSSÍO, Manuel Bartolomé. Sobre la educación estética. Madrid, Boletín de la Institución Libre de Enseñanza, tomo XI, 1887.

${ }^{16}$ Ibidem.

${ }^{17}$ WILLIAMS, Raymond. Cultura e materialismo. São Paulo: UNESP, 2011.

${ }^{18}$ FEBVRE, Lucien. Como reconstruir a vida afectiva de outrora? In:__ . Combates pela história. Lisboa: Presença, 1989.

19 THOMAS, Keith. O homem e o mundo natural. São Paulo: Companhia das Letras, 1989.

${ }^{20}$ THOMPSON, E. P. A miséria da teoria ou um planetário de erros uma crítica ao pensamento de Althusser. Rio de Janeiro: Zahar, 1981. p. 47-61.

${ }^{21}$ Em outras chaves analíticas nos interessam duas outras reflexões: GAY, Peter. $A$ educação dos sentidos. São Paulo: Companhia da Letras, 1987, na qual o autor tematiza a experiência e o desenvolvimento das sensibilidades; e GUMBRECHT, Hans Ulrich. Produção de presença: o que o sentido não consegue transmitir. Rio de Janeiro: Contraponto/Ed. PUC-Rio, 2010. Nessa obra o autor reflete sobre a produção da presença. Ambas dão grande atenção a afetação dos sentidos pelo mundo e ao fato de a chamada modernidade ocidental ter obstado o desenvolvimento de formas menos normativas de fruição e interação corporal, algo que parcialmente seria recuperado pela dimensão estética a partir do séc. XVIII.

22 Diccionario Geral de Lingoa Portuguesa: etymológico, prosódico e orthográphico. 12 ed. Lisboa: A Editora, 1819. SILVA, Antonio de Morais. Diccionario da Lingua Portugueza: recopilado dos vocabularios impressos até agora. Lisboa: Typographia Lacerdina, 1813.

${ }^{23}$ BERRIO, Julio Ruiz. Introducción a la historia de la educación social en España. Historia de la Educación Revista Interuniversitaria, Madri, n. 18, 1999.

${ }^{24}$ Ibidem, p. 7.

${ }^{25}$ ROCHA POMBO, José Francisco da. Supremacia do Ideal. Morretes: Editora do Autor, 1884.

${ }^{26}$ GOMES, Leonardo Ribeiro. "Progredir sempre” os jovens rurais mineiros nos Clubes 4-S: saber, sentir, saúde, servir. (1952-1974). Dissertação (Mestrado em Educação) - Faculdade de Educação, Universidade Federal de Minas Gerais, Belo Horizonte, 2013.

${ }^{27}$ Referências importantes para os propósitos desse trabalho são os estudos de MARDOMINGO, Maria Tejedor. Los movimientos juveniles en la Historia de la Educación Social. Cuadernos de Historia de la Educación, n.4, 2008; e MARTINEZ, Pedro Luiz Moreno. Instituciones y actuaciones circumescolares en la Historia de la Educación Social: reflexiones y propuestas metodológicas para su enseñanza. Cuadernos de Historia de La Educación, n. 4, 2008.

${ }^{28}$ PEREIRA, Lucas. Regulamentando a conduta das meretrizes: dispositivos pedagógicos para a prática do meretrício em Belo Horizonte (1920-1930). Dissertação (Mestrado em Educação) - Faculdade de Educação, Universidade Federal de Minas Gerais, Belo Horizonte, 2012.

${ }^{29}$ TIANA FERRER, Alejandro et al (Ed.). Historia de la educación social. Madrid: UNED, 2014.

${ }^{30}$ FARIA, op. cit., p. 569.

${ }^{31}$ WERNECK, Humberto. O desatino da rapaziada: jornalistas e escritores em Minas Gerais (1920-1970). São Paulo: Companhia das Letras, 2012.

32 TABORDA DE OLIVEIRA; PYKOSZ, op. cit. 
${ }^{33}$ Minas Geraes, n.19, 21 jan. 1894, Seção Collaborações, p. 1 e 2.

${ }^{34}$ SEGANTINI, Verona Campos. Fundando sensibilidades, educando os sentidos: dos sujeitos na cidade. (Belo Horizonte, uma capital no ano de 1900). Dissertação (Mestrado em Educação) - Faculdade de Educação, Universidade Federal de Minas Gerais, Belo Horizonte, 2010.

${ }^{35}$ Minas Geraes, n. 30, 1 fev. 1894, Seção Collaborações, p. 2.

${ }^{36}$ Minas Geraes, n. 40, 11 fev. 1894, Seção Religião, p. 2-3.

${ }^{37}$ SEGANTINI, op. cit.

${ }^{38}$ Minas Geraes, 1894, op. cit.

${ }^{39}$ Minas Geraes, 9 mar. 1894, Seção Collaborações, p. 2.

Artigo recebido em abril de 2014. Aceito em agosto de 2014. 